\title{
THE IDENTIFICATION, ASSESSMENT AND CONTROL OF ENVIRONMENTAL CARCINOGENS IN NSW AND AUSTRALIA
}

\section{Julie Billett}

\section{The Cancer Council NSW}

Within NSW and Australia, a number of agencies are engaged in a wide range of activities - and in deploying a variety of tools-directed towards controlling and managing exposure to environmental carcinogens in industrial, domestic, and agricultural settings, and in the environment. In 2001, The Cancer Council NSW undertook a mapping exercise to establish 'who does what', with respect to the control of environmental carcinogens. The objectives of this exercise were to map out the functions and responsibilities of key state and national organisations involved in the control of environmental carcinogens; to describe the underpinning legislative and regulatory framework; and to identify possible weaknesses and limitations that may exist in the management of environmental carcinogens. This article describes the picture of environmental carcinogen control that emerged from this mapping exercise, which is a picture of a complex array of organisations-working at state and national levels-each with overlapping functions and responsibilities.

Based on current knowledge, over 200 substances, agents, or mixtures are known-or are reasonably anticipated to be-carcinogenic to humans. ${ }^{1,2}$ For the purpose of this exercise, we limited our focus to those chemical and physical agents and substances that are amenable to direct and socially-acceptable control measures, thereby excluding behavioural risk factors for cancer such as diet and physical activity.

Fifteen agencies involved in the control of environmental carcinogens were identified (Table 1). Relevant individuals from each agency were contacted and invited to participate in a semi-structured interview. Information obtained from these interviews was supplemented with information gathered from websites, annual reports, and other literature. In addition, semi-structured interviews were conducted with a second set of organisations with an interest or expertise in environmental carcinogens, including universities, consumer and environmental groups, trade unions, and associations of public and environmental health professionals.

\section{WHO DOES WHAT?}

The infrastructure and activities for the identification, assessment, and control of environmental carcinogens in NSW and Australia is complex. Responsibility is dispersed among multiple agencies, which reflects both the diversity of the substances and agents involved, and the range of settings and routes through which potential exposures could occur. For the majority of agencies involved, their concern with carcinogens is part of a much broader responsibility for environmental and/or public health protection. None, with the possible exception of the Australian Radiation Protection and Nuclear Science Agency (ARPANSA), has a direct focus on carcinogen control per se; nor, unsurprisingly, is there any apparent sense of a community of organisations jointly responsible for environmental carcinogen control. There is also evidence of significant overlap in the organisational responsibilities of the key state and national agencies, with additional complexities imposed by Australia's threetiered system of government at the Commonwealth, state, and local levels.

Taking the two examples of radiation and (carcinogenic) atmospheric contaminants, Table 2 lists those agencies that have an organisational responsibility that includes the assessment, monitoring and/or control of these carcinogens, and provides an indication of the extent of each agency's involvement.

The instruments and measures employed by each of the 15 key agencies for the control of environmental carcinogens reflect the nature of each agency's particular responsibility, as well as any regulatory powers invested

\section{TABLE 1}

FIFTEEN KEY FEDERAL AND STATE AGENCIES RESPONSIBLE FOR THE CONTROL OF ENVIRONMENTAL CARCINOGENS

Australian Nuclear Science and Technology Organisation (ANSTO)

Australia and New Zealand Food Authority (ANZFA)

Australian Radiation Protection and Nuclear Science Agency (ARPANSA)

Commonwealth Department of Health and Aged Care,

Environmental Health Section

Therapeutic Goods Administration (TGA)

Environment Australia

National Occupational Health and Safety Commission (NOHSC)

National Industrial Chemicals Notification and Assessment Scheme (NICNAS)

National Registration Authority for Agricultural and Veterinary Chemicals (NRA)

NSW Agriculture

NSW Environmental Protection Authority (NSW EPA)

NSW Health, Environmental Health Unit

Roads and Traffic Authority NSW (RTA NSW)

Sydney Water Corporation

WorkCover NSW 
by underpinning legislation. A broad spectrum of approaches to control is represented including: the development of policy and guidelines; the setting of standards; the provision of expert advice to government, industry and the public; education, training and information; research, surveillance and monitoring; and the enforcement of regulatory and economic controls.

Besides the 15 agencies involved directly in the mapping exercise, participants identified other agencies with responsibilities that are directly relevant to the control of environmental carcinogens. These include: at the federal level, the National Drugs and Poisons Schedule Committee, the National Health and Medical Research Council and Agriculture, Fisheries and Forestries Australia; and at the state level, Planning NSW, Waste Services NSW, and local government.

\section{LEGISLATIVE AND REGULATORY FRAMEWORK}

The legislative and regulatory framework underpinning carcinogen control in NSW and Australia mirrors the complex picture of overlapping organisational responsibilities described above. This complexity is due to Australia's three-tiered system of government with numerous fields of regulation that have a bearing on carcinogen control. These include regulation in: environmental protection, occupational health and safety, transport and storage of waste, contaminated sites, radiation and nuclear safety, food, tobacco, public health, agricultural and industrial chemicals, urban planning, and land use. Although the Commonwealth Government has some important national responsibilities, particularly with respect to chemicals, therapeutics, food standards, tobacco, and radiation, legislation at the state and territory level gives those jurisdictions extensive responsibilities for managing and controlling exposures to environmental carcinogens in the home, at work, on the farm, and in the environment. A convenient way of differentiating Commonwealth responsibilities from those of the states and territories is that the Commonwealth tends to deal with 'threshold' questions, through activities such as national standard setting and the registration of chemicals. The states and territories tend to regulate the application and/or use of chemicals in places and activities governed by relevant legislation. Local government also has responsibilities in the areas of waste disposal and land use and planning that can potentially affect environmental carcinogen control.

As with other public health issues, Australia's jurisdictions have endeavoured to achieve a degree of uniformity in the laws affecting environmental carcinogen control. ${ }^{3}$ Approaches to legislative uniformity in this area can be thought of as ranging along a continuum, from unitary pieces of Commonwealth legislation that provide for centralised, national controls, such as the Commonwealth Agricultural and Veterinary Chemicals Act 1994, to more cooperative approaches that enable states and territories to legislate for their own codes of practice and other measures, and which are developed through a process of collaboration and consultation with the Commonwealth.

\section{LIMITATIONS AND WEAKNESSES}

All participants in the mapping exercise were asked to highlight any perceived limitations and weaknesses within existing arrangements for environmental carcinogen control in Australia and NSW. A high degree of consistency was evident in the issues raised, despite the diversity of organisational perspectives. The common themes that emerged are summarised below.

\section{System complexity and multiple jurisdictions}

The complexity of the current system of carcinogen controls in NSW and Australia, and the multiple jurisdictions and agencies that contribute, engenders occasional gaps and duplications, and leads to variations

\section{TABLE 2}

ORGANISATIONAL RESPONSIBILITIES FOR THE PREVENTION AND CONTROL OF SELECTED
ENVIRONMENTAL CARCINOGENS IN NSW AND AUSTRALIA

\begin{tabular}{|c|c|c|}
\hline Environmental carcinogen & Core business & $\begin{array}{l}\text { Within organisational responsibility but not core } \\
\text { business }\end{array}$ \\
\hline $\begin{array}{l}\text { Atmospheric contaminants, } \\
\text { including air toxics and } \\
\text { diesel exhaust }\end{array}$ & $\begin{array}{l}\text { - Environment Australia } \\
\text { - NSW EPA (ambient only) } \\
\text { - NSW Department of Health } \\
\text { (Environmental Health Branch) } \\
\text { - RTA NSW }\end{array}$ & $\begin{array}{l}\text { - } \text { ANSTO } \\
\text { - } \text { ARPANSA } \\
\text { - } \text { Commonwealth Department of Health and Ageing } \\
\text { - } \text { TGA Agriculture }\end{array}$ \\
\hline Radiation & $\begin{array}{l}\text { - } \text { ANSTO } \\
\text { - ARPANSA } \\
\text { - NSW EPA }\end{array}$ & $\begin{array}{l}\text { - Commonwealth Department of Health and Ageing } \\
\text { - NSW Department of Health (Environmental } \\
\text { Health Branch) } \\
\text { - NOHSC } \\
\text { - WorkCover NSW }\end{array}$ \\
\hline
\end{tabular}


in approach to the control of carcinogens, particularly in those areas where nationally uniform legislative controls are lacking, such as radiation. Achieving effective communication and coordination between the relevant agencies is perceived as vital to effective carcinogen control, yet is also regarded as a major challenge by the agencies involved. Nationally, a number of cooperative mechanisms have been established in recent years-such as the EnHealth Council, the National Public Health Partnership, and the Chemicals Clearing House-largely as a response to this challenge of improving coordination and communication. Increasingly, agencies operating at the state level see the need to develop more formalised, structured channels for inter-agency working, rather than relying on ad-hoc partnerships on specific projects. Participants also flagged the need for more 'holistic' whole-of-government approaches to environmental and public health policy development. The management of environmental carcinogens and other important environmental health issues requires recognition of their inter-sectoral and interdependent nature, and the development of approaches and structures that support and reinforce joint working. Transport, environmental health, and public health were highlighted by participants as policy areas in which there are clear contradictions and tensions between policy objectives.

\section{Current controls are largely reactive rather than proactive}

New environmental and public health issues are emerging all the time. Although some disease control programs have an element of active surveillance, these tend to focus on acute health problems rather than health outcomes that may result from long-term exposures such as cancers. Participants highlighted a lack of long-term surveillance programs linking environmental and occupational exposures to health outcomes data. Participants also underlined the importance of anticipating changes in the environment, which may predicate new or increased exposures to carcinogens, as a means of facilitating a more precautionary and proactive approach to carcinogen control. These environmental changes may be qualitative in nature; for example, changes to fuel formulations or engine design; or may be quantitative in nature, such as the increase in absolute numbers of diesel vehicles on our roads.

\section{Specific limitations in the control of chemicals}

Under current arrangements for chemical control, existing chemicals are not subject to the same regulatory scrutiny as new chemicals. While the National Industrial Chemicals Notification and Assessment Scheme (NICNAS) and the National Registration Authority for Agricultural and Veterinary Chemicals (NRA) both maintain review schemes for existing chemicals, under which these are reviewed on a priority basis, such schemes only scratch the surface of the thousands of industrial and agricultural chemicals already available for use in Australia. Moreover, there is scepticism among consumers about an assessment process that relies on industry-generated data, and evaluates chemicals on a one-by-one basis, rather than examining the health effects of the total 'chemical load' to which we are exposed. Also of concern is the difficulty of regulating and controlling the use of chemicals in the domestic environment. Reviews commissioned by the National Health and Medical Research Council (NHMRC) have highlighted widespread ignorance of chemical hazards in the home. ${ }^{4}$

\section{Regulatory compliance in occupational settings}

It has been estimated that in excess of 1250 deaths occur each year in Australia as a result of occupational exposure to carcinogens. ${ }^{5}$ Yet relatively little is known about the numbers of people exposed to carcinogenic or potentially carcinogenic substances in the workplace, and the extent and distribution of occupational cancer in Australia. Serious concerns were expressed by participants about the degree of compliance with occupational health and safety regulations and standards governing exposure to hazardous substances, including carcinogens. Several participants highlighted failures or inadequacies in implementing controls for a range of carcinogenic substances, including asbestos, trichloroethylene, and benzene. Itinerant or casual workers employed in small-scale enterprises are thought to be at greatest risk of hazardous exposures. Moreover, the resources available to oversee compliance with occupational health and safety standards are seen as inadequate by the key agencies consulted for this exercise.

\section{Information and skills deficit}

One of the most straightforward themes to emerge was the deficiency of scientific information on many actual and potential carcinogenic hazards. This deficiency was thought to span the range of scientific evidence necessary to undertake robust health risk assessments, from studies of carcinogenesis at the biological and molecular level, to human epidemiological studies of environmental and occupational exposures. Improving our understanding of the toxicity of chemicals and their effect on human and environmental health was seen as a key challenge, as were long-term studies of environmental exposures and an improved understanding of the synergistic effects of particular exposures. This deficiency of knowledge severely limits the ability of organisations to undertake health risk assessments, and to provide robust evidencebased policy advice and recommendations necessary to protect public health. Interviewees also observed a skills shortage in environmental and public health risk assessment, and particularly in relation to the scarcity of toxicological expertise available to public health units across NSW. 


\section{Risk perception and communication}

At a societal level, perceptions of risk drive government policy and ultimately affect the nature of regulatory and other control mechanisms. There is significant public concern about the health risks posed by modern environmental health issues such as environmental pollution, ozone depletion, and chemical exposures. ${ }^{6}$ Yet we have only a limited understanding of environmental risk perception, risk thresholds, risk tolerability, and their determinants in an Australian setting. Improved understanding of public perceptions of environmental and behavioural risk factors, the determinants of those perceptions, and influences over the acceptability or tolerability of risk, would aid environmental and public health practitioners to communicate risk in a meaningful way to the public, and to develop targeted prevention strategies grounded in the evidence from behavioural research.

\section{CONCLUSIONS}

The picture of carcinogen control that emerged from this mapping exercise is of a complex array of organisations working at state and federal levels, each with overlapping responsibilities that include the direct or indirect control of environmental carcinogens. The legislative framework is similarly complex in NSW and Australia. Approaches to joint working on multi-sectoral carcinogen control issues range from formalised cooperative mechanisms to ad-hoc partnerships on specific projects. While no sense emerged of major gaps or holes in the network of controls dealing with established carcinogens, this mapping exercise highlighted some key challenges facing policy makers and practitioners working in the field. Those key challenges and areas for action can be grouped under four broad themes: coordination and cooperation in carcinogen control at national and state levels; enforcement of and compliance with existing controls; information exchange, communication and public engagement; and active management of emerging risks. On a positive note, the key state and national stakeholders consulted saw considerable scope for addressing many of the limitations within existing carcinogen control arrangements, and have demonstrated a commitment to furthering this aspect of cancer control by actively engaging in a strategic program of work being carried forward under the auspices of The Cancer Council NSW.

\section{REFERENCES}

1. National Toxicology Program. Ninth Report on Carcinogens. Research Triangle Park, North Carolina: United States Department of Health and Human Services, 2000.

2. International Agency for Research on Cancer. Monographs series on the evaluation of carcinogenic risks to humans. Lyons, France: IARC, 1972-2001.

3. Centre for Comparative Constitutional Studies, University of Melbourne. Implementation Options for National Legislative Schemes in Public Health. National Public Health Partnership website at www.dhs.vic.gov.au/nphp/legtools/options.

4. National Health and Medical Research Council. A National Plan for Domestic Chemicals. Canberra: AGPS, 1991.

5. Morrell S, Kerr C, Driscoll T, et al. Best estimate of the magnitude of mortality due to occupational exposure to hazardous substances. Occup Environ Med 1998; 55: 63464.

6. Starr G, Langley A, Taylor A. Environmental health risk perception in Australia: A research report to the Commonwealth Department of Health and Aged Care. Centre for Population Studies and Epidemiology, South Australian Department of Human Services. Canberra: AusInfo, 2000.

\section{NSW PUBLIC HEALTH OFFICER TRAINING PROGRAM: PUBLIC HEALTH AND RISK ASSESSMENT AND MANAGEMENT STREAM}

In 2003, the NSW Public Health Officer Training Program will be offering a stream of training in public health risk assessment and management, in addition to its existing generalist and drug and alcohol streams.

The public health risk assessment and management stream is a response to the growing need for people with risk assessment skills, not only in public health emergencies but also for application in environmental and health impact assessments.

For further information about this stream contact the Public Health Training and Development Branch on

(02) 93919204. 